\title{
The Effect of Propolis in Healing Injured Nasal Mucosa: An Experimental Study
}

\author{
Mohammad Waheed El-Anwar ${ }^{1} \quad$ Said Abdelmonem ${ }^{1}$ \\ Kamal El-Kashishy ${ }^{3}$ \\ ${ }^{1}$ Department of Otorhinolaryngology Head and Neck Surgery, Faculty \\ of Medicine, Zagazig University, Zagazig, Egypt \\ ${ }^{2}$ Department of Pharmacology, Faculty of Medicine, Zagazig \\ University, Zagazig, Egypt \\ ${ }^{3}$ Department of Pathology, School of Medicine, Zagazig University, \\ Zagazig, Egypt \\ Int Arch Otorhinolaryngol 2016;20:222-225.
}

\begin{abstract}
Keywords

- nasal mucosa

- propolis

- rat nasal mucosa in rats.

\section{Introduction}

Trauma of the nasal mucosa is common after nasal surgeries, such as endoscopic sinus surgery and septoplasty. Healing of the traumatized nasal mucosa is a highly complex process that involves restoring the anatomical and functional integrity of tissue. ${ }^{1}$ Staffieri et al investigated the effects of nasal corticosteroid sprays on nasal mucosa healing following nasal surgeries. ${ }^{2}$
\end{abstract}

Ahmed A. Abdelsameea ${ }^{2}$ Mohamed AlShawadfy ${ }^{1}$

Address for correspondence Mohammad Waheed El-Anwar, Otorhinolaryngology, Head and Neck Surgery Department, Faculty of Medicine, Zagazig University, Egypt (e-mail: mwenteg@yahoo.com).

Introduction Mechanical trauma to the nasal mucosa increases the risk of synechia formation, especially after chronic rhinosinusitis and nasal surgeries.

Objective This study was carried to assess the effect of propolis administration in healing injured nasal mucosa in rats.

Methods We randomly divided eighteen rats into three equal experimental groups: (1) non-treated group; (2) gum tragacanth (suspending agent for propolis) treated group; and (3) propolis treated group. The non-treated group received no treatment for 15 days. The second group received gum tragacanth administration $(5 \mathrm{ml} / \mathrm{kg}$, orally) once daily for 15 days. The third group received propolis suspension orally at a dose of $100 \mathrm{mg} / \mathrm{kg}$ once daily for 15 days. At the beginning of this study, we induced unilateral mechanical nasal trauma on the right nasal mucosa of all rats in the three groups using a brushing technique. A pathologist stained tissue samples using hematoxylin and examined eosin by using a light microscope.

Results The severity of inflammation was milder with the absence of ulcerations in the propolis treated group compared with the non-treated and gum tragacanth groups. Goblet cell and ciliated cell loss was substantially lower in patients treated with propolis compared with groups without treatment and those treated with gum tragacanth. Conclusion Propolis decreased inflammation and enhanced healing of wounds of the

received

October 28, 2015

accepted

December 16, 2015

published online

February 26, 2016
DOI http://dx.doi.org/ 10.1055/s-0036-1579664. ISSN 1809-9777.
Propolis is a resinous bee-hive product consisting of plant materials collected by worker bees. Bees chew on such materials, then, salivary enzymes are added and mixed with wax to produce propolis. ${ }^{3}$ Flavonoids and esters of caffeic acid are the most biologically active fractions of propolis. ${ }^{4}$

Propolis has anti-inflammatory, ${ }^{5}$ anti-oxidant, ${ }^{6}$ antimicrobial, $^{7}$ and, especially, anti-bacterial ${ }^{8}$ actions. Furthermore, the propolis component known as caffeic acid is potent

Copyright $\odot 2016$ by Thieme Publicações License terms Ltda, Rio de Janeiro, Brazil

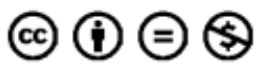


in inhibiting pro-inflammatory proteinase, matrix metalloproteinase-9, which is known to be increased in ulcers. ${ }^{9}$

Propolis has proven to be a helpful topical treatment for ulcers. ${ }^{3}$ Thus, many countries have approved it for the treatment of ulcers and abrasions. ${ }^{3}$ Propolis is also considered to have a low side-effect profile. ${ }^{10}$

The present study aims to assess the effect of propolis on healing of the nasal mucosa after iatrogenic trauma to nasal mucosa in rats.

\section{Materials and Methods}

\section{Drugs and Chemicals}

Ethylenediamine Tetra Acetic Acid (EDTA) powder (El-Nasr Pharmaceutical Chemical Company), Ketamine Hydrochloride (Troikaa Pharmacuticals LTd. Gujarat, India $50 \mathrm{mg}(10 \mathrm{ml})$ vial), Propolis (propolis supplied as brown powder purchased from Medicinal Plants Company) and Gum tragacanth (Supplied as powder, El Gomhoria Company for drugs and Chemicals).

\section{Animals}

In this study we used eighteen adult male Wistar rats, weighing 200 to $250 \mathrm{~g}$. The rats were kept under proper environments according to the standard guidelines and in suitable cages that were maintained under standard conditions (average room temperature $22 \pm 2^{\circ} \mathrm{C}, 12$-hour dark and light cycles). Prior to being euthanized, the animals had free access to water and were fed a conventional laboratory diet. All experimental protocols received approval from the ethics committee.

All rats were anesthetized with ketamine hydrochloride $(100 \mathrm{mg} / \mathrm{kg}$, IM). Unilateral mechanical nasal trauma using a brushing technique by interdental brush was performed on the mucosa of right nasal cavity of all rats in all groups. ${ }^{11}$

We randomly categorized the 18 rats into three equal groups: (1) the non-treated control group; (2) the gum tragecanthtreated group received $5 \mathrm{ml} / \mathrm{kg} 5 \%$ gum tragacanth (suspending agent for propolis) by gavage once daily for 15 days; (3) the propolis-treated group, where rats received $100 \mathrm{mg} / \mathrm{kg}$ propolis suspension, once daily for 15 days. Propolis was suspended in $5 \%$ gum tragacanth in a ratio of four-to-one, respectively. ${ }^{12}$

\section{Tissue Preparation}

Under clean but non sterile conditions, we performed all surgical procedures. At the end of 15 days, after the induction of anesthesia, the rats were decapitated. By microdissection, we excised the nose of each rat, fixing them in 10\% formaldehyde solution for 24 hours and decalcifying in 10\% ethylene diamine tetra acetic acid (EDTA) solution for 3 weeks. Then the nasal septa were carefully removed with scissors. After that, we rinsed the septa in tap water for 24 hours, dehydrated them utilizing a graded alcohol series rendered transparent and blocked following infiltration with paraffin. With a microtome (Microm HM 360), the paraffin-embedded samples were sliced to a thickness of $5 \mu \mathrm{m}$ slices that were stained with hematoxylin and eosin (H\&E) before light microscope examination by the pathologist, who was blinded to the study groups. We determined the severity of loss of ciliated and goblet cells by comparison of injured with contralateral side. We histologically categorized the degree of inflammation, ciliated cell loss, and goblet cell loss as follows: $(+)$ mild, $(++)$ moderate, and $(+++)$ severe according to wound healing indices. ${ }^{11}$

\section{Statistical Analysis}

The results obtained were statistically analyzed using the SPSS 15.0 software package for Windows (SPSS Inc., Chicago, IL). We compared the differences in histological scores between the control, gum tragacanth, and propolis groups using Fisheís exact test. Statistical significance was considered for $p<0.05$.

\section{Results}

Moderate to severe inflammation was reported in the nontreated and gum tragecanth-treated groups, whereas in the propolis group, the degree of inflammation was mild to moderate ( - Table 1; - Figs. $1-3$ ), with statistically significant difference $(p=0.0141,-$ Table 1$)$.

We also found the severity of ciliated and goblet cell loss to be moderate to severe in the non-treated and gum tragacanth-treated groups (-Table 2; - Figs. 1 and 2). On the other hand, the ciliated and goblet cells were mostly preserved in the propolis group (-Fig. 3). The statistical difference between propolis and other groups was significant $(p=0.0073$, -Table 2)

\section{Discussion}

Many negative sequels could occur during healing of the nasal mucosa, including excessive crust formation and synechia. These cause failure or recurrence of the initial disease after nasal surgeries such as septoplasty and endoscopic sinus surgery. Iatrogenic trauma to the inflamed nasal mucosa, particularly after surgeries for chronic rhinosinusitis, increases the risk of synechia that could lower the postsurgical success chances. Careful postoperative care of the nasal cavity aims to avoid such complications and improve the healing process. The known anti-bacterial and antiinflammatory characteristics of propolis ${ }^{13}$ make it a natural target for wound healing studies.

The results of the current study showed that propolis administration reduced severity of inflammation and preserved the ciliated as well as goblet cells after experimental trauma of nasal mucosa. Absence of ulcerations in the propolis-treated group means that the process of healing is enhanced after administration of this agent. By contrast, the non-treated and gum

Table 1 Severity of inflammation

\begin{tabular}{|l|l|l|l|}
\hline Groups & $\begin{array}{l}\text { Mild } \\
\text { (number) }\end{array}$ & $\begin{array}{l}\text { Moderate } \\
\text { (number) }\end{array}$ & $\begin{array}{l}\text { Severe } \\
\text { (number) }\end{array}$ \\
\hline Non-treated & 0 & 2 & 4 \\
\hline $\begin{array}{l}\text { Gum } \\
\text { tragacanth-treated }\end{array}$ & 0 & 3 & 3 \\
\hline Propolis-treated & 4 & 2 & 0 \\
\hline
\end{tabular}

Note: $p=0.0141$; Fisheís exact test was applied. 


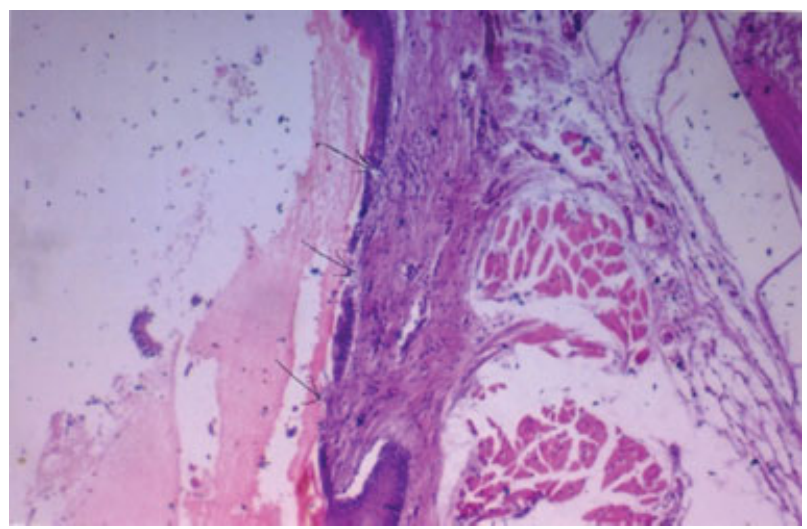

Fig. 1 Photomicrograph from non-treated control group showing nasal mucosa with areas of ulceration, goblet, and ciliated cell loss as well as severe inflammatory cellular infiltrate in submucosa [H\&E, 200].

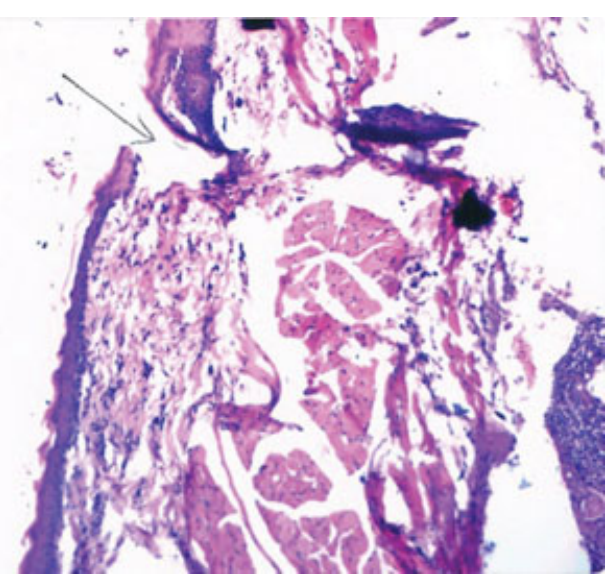

Fig. 2 Photomicrograph from gum tragecanth-treated group showing nasal mucosa with areas of ulceration, goblet, and ciliated cell loss as well as severe inflammatory cellular infiltrate in submucosa [H\&E, 200].

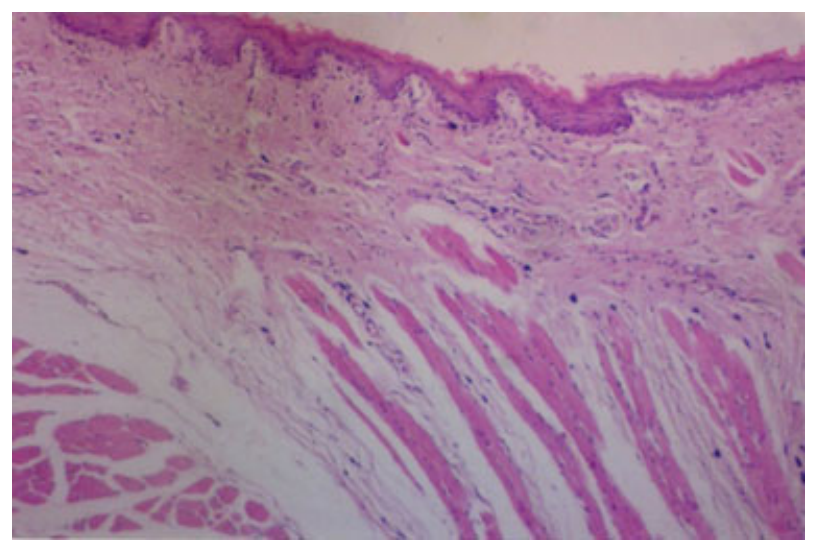

Fig. 3 Photomicrograph from propolis-treated group showing nasal mucosa with mild inflammatory infiltrate in the submucosa [H\&E 200].

tragacanth groups showed severe inflammation and ulceration with loss of ciliated and goblet cells.

These results agree with Henshaw et al, ${ }^{14}$ who found that topical propolis enhanced wound healing in human diabetic foot ulcer and accelerated wound closure in this setting when applied weekly. They reported that propolis had demonstrable antibacterial effect leading to decreasing bacterial load in the diabetic
Table 2 Severity of goblet and ciliated cells loss

\begin{tabular}{|l|l|l|l|}
\hline Groups & $\begin{array}{l}\text { Mild } \\
\text { (number) }\end{array}$ & $\begin{array}{l}\text { Moderate } \\
\text { (number) }\end{array}$ & $\begin{array}{l}\text { Severe } \\
\text { (number) }\end{array}$ \\
\hline Non-treated control & 0 & 3 & 3 \\
\hline $\begin{array}{l}\text { Vehicle-treated } \\
\text { control }\end{array}$ & 0 & 4 & 2 \\
\hline Propolis-treated & 5 & 1 & 0 \\
\hline
\end{tabular}

Note: $p=0.0073$; Fisheŕs exact test was applied.

foot ulcer. Moreover, Kinis et al ${ }^{1}$ found that caffeic acid phenethyl ester, one of the active components of propolis, had a beneficial effect on the wound healing of rat nasal mucosa.

More than three hundred different compounds have been known so far in propolis, comprising aliphatic acids, esters, fatty acids, aromatic acids, aldehydes, carbohydrates, amino acids, chalcones, dihydrochalcones, terpenoids, ketones, vitamins, and inorganic substances. Flavonoids draw greater research interest than other compounds. ${ }^{15}$

The in vitro antibacterial activity of propolis results from synergistic actions between propolis compounds, mainly pinocembrin and galangin flavonoids, and was proven against several Gram-negative and Gram-positive bacteria. Other flavonoids, such as chrysin and kaempferol, showed antiviral activity reducing intracellular proliferation of some viruses, such as herpes simplex. ${ }^{16}$

The tissue changes induced by trauma and the possible infection lead to the generation of inflammatory mediators that cause subsequent inflammatory events. Release of IL-1 and TNF- $\alpha$ by activated macrophages results in vasodilatation and leads to smooth muscle relaxation and increased local blood flow. Microvascular changes associated with increased vascular permeability occur, resulting in enhanced plasmatic exudation, phagocyte accumulation (neutrophils, macrophages, and monocytes), and amplification of endogenous chemical mediators. At the same time, phagocytic cells, mast cells, and endothelial cells utilize plasma membrane lipids to produce important inflammatory mediators. ${ }^{17}$

Propolis is a potential anti-inflammatory agent for acute and chronic stages. ${ }^{18}$ Mice and rabbit studies have proved that hydro alcoholic solutions of propolis have anti-inflammatory activity following injectable, topical, or oral administration. ${ }^{16}$ Further study is needed to assess the effect of topical application of propolis in the injured nasal cavity.

\section{Conclusion}

Systemic administration of propolis enhances healing of experimentally injured nasal mucosa most probably due its anti-inflammatory and antimicrobial effects. Further study is needed to assess the effect of local application of propolis in the nasal cavity.

\section{Conflict of Interest and Financial Disclosure}

The authors declare no financial support to this study and declare no conflict of interest. 


\section{References}

1 Kınıs V, Ozbay M, Akdag M, et al. Effects of caffeic acid phenethyl ester on wound healing of nasal mucosa in the rat: an experimental study. Am J Otolaryngol 2014;35(4):482-486

2 Staffieri A, Marino F, Staffieri C, et al. The effects of sulfurousarsenical-ferruginous thermal water nasal irrigation in wound healing after functional endoscopic sinus surgery for chronic rhinosinusitis: a prospective randomized study. Am J Otolaryngol 2008;29(4):223-229

3 Wagh VD. Propolis: a wonder bees product and its pharmacological potentials. Adv Pharmacol Sci 2013;2013:308249

4 Banskota AH, Nagaoka T, Sumioka LY, et al. Antiproliferative activity of the Netherlands propolis and its active principles in cancer cell lines. J Ethnopharmacol 2002;80(1):67-73

5 Grunberger D, Banerjee R, Eisinger K, et al. Preferential cytotoxicity on tumor cells by caffeic acid phenethyl ester isolated from propolis. Experientia 1988;44(3):230-232

6 Talas ZS, Ozdemir I, Ciftci O, Cakir O, Gulhan MF, Pasaoglu OM. Role of propolis on biochemical parameters in kidney and heart tissues against L-NAME induced oxidative injury in rats. Clin Exp Hypertens 2014;36(7):492-496

7 Gekker G, Hu S, Spivak M, Lokensgard JR, Peterson PK. Anti-HIV-1 activity of propolis in $\mathrm{CD} 4(+)$ lymphocyte and microglial cell cultures. J Ethnopharmacol 2005;102(2):158-163

8 Astani A, Zimmermann S, Hassan E, Reichling J, Sensch KH, Schnitzler P. Antimicrobial activity of propolis special extract GH 2002 against multidrug-resistant clinical isolates. Pharmazie 2013;68(8):695-701
9 Liu Y, Min D, Bolton T, et al. Increased matrix metalloproteinase-9 predicts poor wound healing in diabetic foot ulcers. Diabetes Care 2009;32(1):117-119

10 Gallo E, Lucenteforte E, Firenzuoli F, et al. Herbalists' perception of risks involving commonly sold medicinal plants in Italy. Complement Ther Med 2014;22(1):81-86

11 Khalmuratova R, Jeon SY, Kim DW, et al. Wound healing of nasal mucosa in a rat. Am J Rhinol Allergy 2009;23(6):e33-e37

12 Shukla S, Bhadauria M, Jadon A. Effect of propolis extract on acute carbon tetrachloride induced hepatotoxicity. Indian J Exp Biol 2004;42(10):993-997

13 McLennan SV, Bonner J, Milne S, et al. The anti-inflammatory agent Propolis improves wound healing in a rodent model of experimental diabetes. Wound Repair Regen 2008;16(5):706-713

14 Henshaw FR, Bolton T, Nube V, et al. Topical application of the bee hive protectant propolis is well tolerated and improves human diabetic foot ulcer healing in a prospective feasibility study. J Diabetes Complications 2014;28(6):850-857

15 Havsteen BH. The biochemistry and medical significance of the flavonoids. Pharmacol Ther 2002;96(2-3):67-202

16 Marcucci MC. Propolis: Chemical composition, biological properties and therapeutic activity. Apidologie (Celle) 1995; 26:83-99

17 Lopes RE, Chapadeiro E, Raso P, et al. Patologia. Guanabara 1987; 67-112

18 Borrelli F, Maffia P, Pinto L, et al. Phytochemical compounds involved in the anti-inflammatory effect of propolis extract. Fitoterapia 2002;73(1):S53-S63 